IOURNALOF

\title{
Grupo de ouvidores de vozes do Instituto de Psiquiatria do Rio de Janeiro: funcionamento e prática
}

\section{Group of voices hearers of the Institute of Psychiatry of Rio de Janeiro: operation and practice}

\section{Grupo de oyentes de voces del Instituto de Psiquiatría de Rio de Janeiro: funcionamiento y práctica}

Herreira, Lieni Fredo ${ }^{1}$; Bica, Suélen Cardoso Leite ${ }^{2}$; Lemos, Duilia Sedrês Carvalho ${ }^{3}$; Oliveria, Michele Mandagará de ${ }^{4}$

Como citar este artigo: Herreira LF, Bica SCL, Lemos DSC, Oliveira MM. Grupo de ouvidores de vozes do Instituto de Psiquiatria do Rio de Janeiro: funcionamento e prática. J. nurs. health. 2018;8(n.esp.):e188420

Palavras-chave: Saúde mental; Terapêuticas; Ouvidores de vozes.

\section{APRESENTAÇÃO}

As narrativas aqui apresentadas foram realizadas no Primeiro Congresso Nacional de Ouvidores de Vozes no Brasil, realizado na cidade do Rio de Janeiro nos dias 20 e 21 de outubro do ano de 2017. Teve como objetivo inicial: discutir a relevância do protagonismo do usuário em processos de reabilitação psicossocial e superação de crises. Esse congresso surgiu após a realização de workshops anteriormente realizados para discutir a temática no cenário nacional.

A entrevista narrativa é utilizada por sua potencialidade em proporcionar a vivência pessoal e propor autorreflexão sobre os eventos. Nesse tipo de entrevista o foco está na maneira como os seres humanos expressam suas experiências. ${ }^{1}$

\section{O começo do grupo ouvidores de vozes}

\section{Octávio Domont de Serpa Júnior}

Meu primeiro contato com grupos de ouvidores de vozes, aconteceu há mais de 20 anos, quando eu trabalhava em um Hospital Dia particular da Associação Casa

\footnotetext{
${ }^{1}$ Enfermeira. Universidade Federal de Pelotas (UFPEL). E-mail: lieniherreiraa@hotmail.com http: //orcid.org/0000-0003-2069-3839

2 Enfermeira. Mestre em Ciências. Universidade Federal de Pelotas (UFPEL) E-mail: suellehn@gmail.com http://orcid.org/0000-0001-7513-9769

3 Psicóloga. Universidade Federal de Pelotas (UFPEL). E-mail: duilia.carvalho@gmail.com http://orcid.org/00000001-6561-1561

4 Enfermeira. Doutora em Enfermagem. Universidade Federal de Pelotas (UFPEL). E-mail: mandagara@hotmail.com http://orcid.org/0000-0002-7914-9339
} 


\section{JOURNALOF

Verde, onde foi montado um grupo de ouvidores de vozes após os usuários do serviço sentirem necessidade de um local onde pudessem falar sobre as vozes que ouviam.

Os dias de reunião foram instituídos conforme os turnos em que eu estava no hospital, e foi uma experiência muito positiva naquela época. $E$ eu não tinha conhecimento que naquela época o assunto já era muito discutido na Holanda, pois as informaçõos não circulavam com tanta rapidez como hoje.

Em 2004 comecei a trabalhar no Instituto de Psquiatria da Universidade Federal do Rio de Janeiro (IPUB/UFRJ) e então eu, Núria Malajovich Muñoz e a Erotildes Maria Leal iniciamos uma atividade no laboratório de pesquisa em psicopatologia e subjetividade que visava instalar no Hospital Dia do IPUB um grupo de ouvidores de vozes. Então conseguimos iniciar este grupo em 2004, e tivemos o apoio também da Catarina e a Iraneide Oliveira, e devido a nossas inúmeras atividades como docentes, acabamos priorizando outras pesquisas e desativando o grupo em 2008.

Então em 2015, com a execução dos primeiros workshops, vinda do professor Marius Homme, e o ingresso da Octávia Barros no mestrado trabalhando o tema de ouvidores de vozes, o Abmael de Sousa Alves juntou-se com ela e assim o grupo de ouvidores de vozes aqui no IPUB foi reativado.

\section{Abmael de Sousa Alves}

Em 2015 também eu, Abmael de Sousa Alves, conheci a Octávia Barros, o Octávio Domont de Serpa Junior e a Erotildes Maria Leal e juntos tivemos um treinamento com o Paul Baker que ocorreu aqui no auditório para que fosse realizado grupos de ouvidores de vozes dentro do Hospital Dia aqui do IPUB. Como era um desejo implantar esses grupos, aproveitei a parceira com a Octávia que estava ingressando no mestrado para trabalhar está temática.

\section{O funcionamento do grupo de ouvidores de vozes}

\section{Abmael de Sousa Alves}

0 grupo tem funcionado todas as quintas ferias às três da tarde, ele é aberto a população em geral, não precisando ser ouvidor de vozes, e não é apenas da instituição, abrange inclusive outros municípios ao redor do Rio de Janeiro. 0 diferencial do nosso grupo tem sido a escuta ao sujeito, saindo do modo tradicional que é a medicalização, percebemos o quanto é importante realizar essa troca de experiências com eles também.

Eu e a Octávia Barros, estamos há um tempo discutindo sobre a forma que os usuários nos veem, não queremos ser vistos como coordenadores e sim como facilitadores, por que o grupo não funciona apenas com conversas sobre as vozes, mas sim como diversas temáticas que são trazidas pelos integrantes, facilitando assim a interação de todos.

Nós também temos apoio dos estagiários do serviço social, terapia ocupacional e psicologia, e as vezes ficamos nos perguntando se realmente precisamos estar ali 
para coordenar o grupo, já que os participantes se integram bem e de forma muito dinâmica, porém percebemos também a riqueza nas trocas entre nós profissionais e os integrantes do grupo.

Então o grupo funciona de forma bem dinâmica, tem momentos que os próprios usuários coordenam as reuniões, fazendo com que eles realmente percebam que o grupo é de todos e para todos, tanto para os ouvidores de vozes, que relatam suas experiências com suas vozes, como para as pessoas que não escutam vozes mas que estão ali para trocar suas experiências de vida e aprender mais sobre este assunto.

\section{Os participantes do grupo}

\section{Abmael de Sousa Alves}

O grupo é formado de oito a doze participantes, e por ele ser aberto as vezes temos integrantes que são visitantes, que vem acompanhar algum familiar e participam da reunião naquele dia. As vezes os usuários encontram dificuldades em acessar o serviço devido ao deslocamento e o engarrafamento que muitas vezes eles encontram ao voltar para casa, o que gera um estresse grande e demora para voltar para casa.

Nós não limitamos o número de integrantes nas reuniões até por que gosto muito de grupos bem grandes. Em relação a integrantes novos, podem entrar a qualquer momento, e quando isso acontece ele é acolhido pelas pessoas que estão mais tempo aqui.

\section{REFERÊNCIA}

1 De Moura JF. A entrevista narrativa: dispositivo de produção e análise de dados sobre trajetórias de professoras. Cad pes [Internet]. 2017[acesso em 2018 set 03];24(1):2178-229. Disponível em: http://dx.doi.org/10.18764/21782229.v24n1p15-30 